\title{
Factors associated with malnutrition among head and neck cancer in-patients before radiotherapy in National Cancer Institute, Putrajaya
}

\author{
Neoh May Kay ${ }^{1,2}$, Zalina Abu Zaid ${ }^{1 *}$, Zuwariah Abdul Rahman ${ }^{2}$, Norshariza \\ Jamhuri $^{1,2}$, Zuliehaiza Kahairudin ${ }^{2}$, Siti Noraini Ahmad Samwil ${ }^{2}$, Aeininhayatey \\ Abdullah $^{2}$, Ho Chiou Yi ${ }^{1,2}$, Betti Sharina Haniff Lai ${ }^{2}$, Ng Wai Han ${ }^{2}$, Aini Masitah \\ Mohammad $^{1,2}$, Nor Baizura Md Yusop ${ }^{1}$, Zuriati Ibrahim ${ }^{1}$ \& Zulfitri 'Azuan Mat \\ Daud $^{1}$
}

${ }^{1}$ Department of Nutrition and Dietetics, Faculty of Medicine and Health Sciences, Universiti Putra Malaysia, Selangor, Malaysia; ${ }^{2}$ Dietetic and Food Service Department, National Cancer Institute, Putrajaya, Malaysia

\begin{abstract}
Introduction: Head and neck cancer (HNC) patients are often malnourished during diagnosis and before treatment. This study determined the prevalence of malnutrition and factors associated with malnutrition among HNC patients. Methods: A crosssectional study among HNC in-patients before radiotherapy was conducted. Malnutrition status of the patients was determined using scored Patient GeneratedSubjective Global Assessment (PG-SGA). Nutritional parameters of muscle mass, fat mass, albumin, energy and protein intakes were collected. Nutrition impact symptoms (NIS) of the patients were assessed using a validated Head and Neck Symptoms Checklist $^{\odot}\left(\mathrm{HNSC}^{\odot}\right)$. Results: Fifty HNC patients were recruited in this study and the age range of patients was 21 to 78 years old, with gender distribution of $78 \%$ males and $22 \%$ females. More than half of the patients were malnourished, with $20 \%$ severely malnourished before radiotherapy. The lack of dietitian referral before treatment was found to significantly affect nutritional status $(p=0.027)$. There was a significant negative relationship between energy intake $(r=0.342, p=0.015)$ and protein intake $(r=0.386, p=0.006)$ with PG-SGA, indicating lower energy and protein intakes related with poor nutritional status. The result showed a significant positive relationship between NIS score $(r=0.731, p<0.001)$ and PG-SGA, indicating the lower the NIS, the better the nutritional status among HNC patients. More than half of the HNC patients had difficulty chewing. Conclusion: A strong association between nutritional status and NIS showed the importance of dietary management in HNC patients. Early identification of the nutritional status of HNC patients can ensure optimal nutritional status to improve treatment outcomes.
\end{abstract}

Keywords: Head and neck cancer, nutritional status, nutrition impact symptoms, energy intake, protein intake

\section{INTRODUCTION}

Head and neck cancers (HNC) are malignancies in the head and neck region, which includes the oral and nasal cavities, sinuses, salivary glands, pharynx, larynx and lymph nodes in the neck (Stewart \& Wild, 2014). It is the sixth most common cancer worldwide.

\footnotetext{
*Corresponding author: Zalina Abu Zaid

Department of Nutrition and Dietetics, Faculty of Medicine and Health Sciences

Universiti Putra Malaysia, Malaysia

E-mail: zalina@upm.edu.my

doi: https: / /doi.org/10.31246/mjn-2019-0094
} 
The incidence of oral cavity and pharyngeal cancers has been the highest in Southeast Asia, Western and Central Europe, and South America (Chaturvedi et al., 2013). A total of 103,507 new cancer cases were diagnosed among Malaysians from 2007 to 2011, and the report indicated that $\mathrm{HNC}$ contributed $10 \%(10,608)$ of the cases (Azizah et al., 2015). Nasopharynx cancer is one of the HNC and is the third most common cancer among Malaysian men (Azizah et al., 2015).

The current treatment of advanced HNC requires multimodal therapy. Surgery, radiotherapy (RT), concurrent chemotherapy and radiotherapy (CCRT) have become standards of care for HNC patients. Prior to RT or CCRT treatment, HNC patients undergo either surgery or neoadjuvant chemotherapy to shrink the size of their tumour, depending on patients' clinical conditions. According to Prevost's review study, optimal nutritional status before treatment is able to improve the effectiveness of treatment and treatment outcomes (Prevost et al., 2014).

However, HNC patients are often malnourished at the time of diagnosis, before treatment or during treatment due to the catabolic state induced by the malignancy and the potential for dysphagia caused by an obstructing tumour (Bower \& Martin, 2009). In individuals with HNC, their weight may be affected by the tumour location and related symptoms that interfere with dietary intake. These symptoms are referred to as nutritional impact symptoms (NIS), which include loss of appetite (LOA), nausea, vomiting, taste change, anxiety, depression, difficulty swallowing, pain, dry/sore mouth, difficulty chewing, dental problems, thick saliva, and constipation (Kubrak et al., 2010).

Various studies that have been done previously have shown the prevalence of weight loss before HNC treatment to be between $19 \%$ and $45 \%$, which is an indicator of subacute malnutrition (Jager-Wittenaar et al., 2007; Lees, 1999; van den Berg et al., 2006). Malnutrition before treatment due to insufficient food intake is mostly related to mechanical obstruction of food or pain caused by the tumour (Luis, Izaola \& Aller, 2007). Cachexia that is associated with muscle wasting with or without the loss of fat mass has contributed to malnutrition as well (Evans et al., 2008). Swallowing problems and pain in the mouth are identified as main risk factors for malnutrition in HNC patients before treatment (Jager-Wittenaar et al., 2007; Kubrak et al., 2010; Righini et al., 2013). Jager-Wittenaar et al. (2007) has suggested that total nutrition impact symptoms score could be assessed and addressed as part of a comprehensive care plan in order to optimise the nutritional status of patients before commencing treatment.

Nutrition is a significant aspect in HNC patient management. It determines a patient's functional status, tolerance towards treatment, and overall prognosis. A survey conducted by Spiro et al. (2006) demonstrated insufficient detection of malnutrition among 334 oncologists, with only one third having assessed weight loss during consultation, and $65 \%$ indicated the importance of malnutrition. Currently, HNC patients in the National Cancer Institute (NCI), Putrajaya are seldom referred to dietitians at diagnosis, instead, they are only referred when having inadequate dietary intake during RT. Dietitian referral is important to identify those who have malnutrition problems in order to optimise nutritional status before treatment. Therefore, nutritional assessments including dietary assessment and nutrition impact symptoms before treatment are important for early nutrition intervention to improve the effectiveness of treatment (Righini et al., 2013). 
There is a lack of study in Malaysia to evaluate the prevalence of malnutrition among patients with HNC at the time of initial management (pre-treatment). The purpose of the present study is to determine the prevalence of malnutrition among HNC patients before RT and to examine the associations between pre-treatment weight loss, laboratory parameters, dietary intake, protein intake, and NIS score with malnutrition.

\section{MATERIALS AND METHODS}

\section{Study design and setting}

This study was part of a prospective study about the changes in nutritional status among HNC patients during RT. Consecutive sampling was used to enrol every HNC patient who was admitted to receive RT or CCRT at NCI, Putrajaya, from March until December 2018, based on inclusion criteria and their informed consents, until the desired sample size was achieved. RT patients received a RT dosage between 60Gy to 70Gy in daily factions of 2.0Gy within seven weeks, while CCRT patients received additional weekly cisplatin or carboplatin during the seven weeks of RT. The inclusion criteria were HNC patients who were admitted into the ward for undergoing RT for seven weeks with or without chemotherapy for curative treatment intentions and aged $\geq 18$ years. Besides that, patients were also on $100 \%$ oral intake at the time of the study, and without any forms of enteral tube feeding or total parenteral nutrition. Patients were excluded from this study if they were involved in another research project and ongoing artificial nutrition (enteral/ parenteral) before RT or CCRT.

\section{Ethical approval}

This study was registered with The National Medical Research Registry (NMRR ID 17-2647-37667). Ethical approval for the study was obtained from the Medical Research Ethics Committee (MREC), Ministry of Health Malaysia and the Medical Research Ethics Committee of the Faculty of Medicine \& Health Sciences, Universiti Putra Malaysia. Permission to conduct the study was obtained from the Director, NCI, Putrajaya, Malaysia.

\section{Socio-demographic and clinical characteristics}

Socio-demographic data collected included age, gender, ethnicity, marital status, occupation, and education level. For clinical characteristics, they included tumour location and stage, type of treatment, duration and dosage of RT. These were obtained from the computerised Hospital Information System (HIS). Co-morbidities, smoking status, alcohol consumption and family history before RT were collected.

\section{Nutritional status}

Malnutrition status

The malnutrition status of patients was determined by using the PatientGenerated Subjective Global Assessment (PG-SGA). The PG-SGA is a global rating and scoring nutritional assessment tool specialised for cancer patients (Bauer, Capra \& Ferguson, 2002). This instrument is a subjective questionnaire with closed-ended structure. The first part of the questionnaire included weight loss history, dietary intake, activities and functions, while the second part was about the patient's disease and its relation to nutrition requirements. The metabolic demand (stress) and physical examination were filled out by a physician, trained nurse or dietitian who assessed the patient's metabolic and physical demands (Ottery, McCallum \& Polisena, 2000). Patients were subjectively categorised as well-nourished (PG-SGA category A), moderately or suspected of being malnourished (PGSGA category B) or severely malnourished (PG-SGA category $C$ ) upon the completion of the assessment. The scored PG-SGA is a further development of the subjective 
global assessment (SGA) concept that incorporates a numerical score. A score ranging from 0 to 4 was given for each domain, depending on the impact on nutritional status. A high score indicated a lower nutritional status of the patient, thus requiring nutrition intervention. Scores with 0 to 1 point requires no intervention, health education for those with 2 to 3 points, dietetic intervention for those with 4 to 8 points, and nutrition support for those with $>9$ points.

\section{Anthropometric measurements}

Anthropometric measurements used in this study included body weight, height, and body composition. Body height was measured using a stadiometer (Seca 222, medical scales \& measuring systems Seca, United Kingdom). Measurements of body weight and body composition were assessed with a calibrated TANITA total body composition analyser (model SC300, bioelectrical impedance analysis scales, Japan), which can provide body weight in $\mathrm{kg}$ (up to $0.1 \mathrm{~kg}$ ), fat percentage (up to $0.1 \%$ ), and total muscle mass (up to $0.1 \mathrm{~kg})$. The patients were required to be bare footed and to stand upright and front facing during measurement. The patients were requested to have minimal clothing, emptied their pockets, and stand upright while barefooted on the metal plate of the scale.

Body mass index (BMI) was calculated as actual body weight/height ${ }^{2}$ in $(\mathrm{kg} /$ $\mathrm{m}^{2}$ ). BMI was then classified as either underweight $\left(\mathrm{BMI}<18.5 \mathrm{~kg} / \mathrm{m}^{2}\right)$, normal (BMI 18.5-24.9 kg/m²), overweight (BMI $25-29.9 \mathrm{~kg} / \mathrm{m}^{2}$ ) or obese (BMI $>30 \mathrm{~kg} /$ $\mathrm{m}^{2}$ ) (WHO, 2004). Percentage weight loss was calculated as (normal body weight - actual body weight)/ (normal body weight) $x$ 100. Normal body weight was defined as the body weight one month before treatment and was retrieved from medical records. Actual body weight was assessed at the beginning of treatment.

\section{Laboratory parameters}

Data on serum albumin, haemoglobin
(Hb) and white blood cells (WBC) count at the beginning of treatment were extracted from the patient's medical record. This is a standard routine procedure for blood sampling to monitor the patient's clinical condition.

\section{Dietary intake (energy and protein intakes)}

Dietary intake was measured through a one day 24-hour dietary recall. Foods and beverages consumed in the last 24 hours, starting from the last midnight and finishing at midnight, were identified by 24-hour dietary recall. This questionnaire consisted of six meals including breakfast, lunch, dinner and three snacks. Intakes of foods in household servings, and subsequently in grams, were collected for every meal to estimate energy and macronutrient intakes. Household measurements were used to calculate the grams of foods consumed. For this purpose, a set of household measurement tools (glass, soup bowl, plate, cup, teaspoon and tablespoon) and food models were used to guide patients in estimating portion sizes. Then, the intakes of energy and macronutrients were determined. The Nutritionist Pro software was used to analyse information on the amount of macronutrient intakes (in gram) and total energy intake (kcal) by entering the meals' recipes with the exact gram intake of all food items. The software calculated the nutrition facts of all the foods taken in a day from recall. Data on total energy and protein intakes were recorded to compare with the energy requirement of patients.

\section{Functional status}

Functional status was measured by handgrip strength using the Jamar hand dynamometer (Fred Sammons Inc, Burr Ridge, Illinois, USA). Patients sat with their shoulder adducted and neutrally rotated, elbow flexed at $90^{\circ}$, forearm in neutral position. Standard verbal instructions were given to the 
patients to squeeze the dynamometer as hard as possible for three times after an interval of five seconds in between grips. The average of three successive attempts on the non-dominant hand was used as the final result. The handgrip strength results were then descriptively compared with reference values from the other two studies among cancer patients, whereby low hand-grip strength was defined as grip strength $<25 \mathrm{~kg}$ (Chen et al., 2011). High strength was defined as above $19.84 \mathrm{~kg}$ in women and 34.39 $\mathrm{kg}$ in men; while intermediate strength was considered between $14.68 \mathrm{~kg}$ and $19.84 \mathrm{~kg}$ in women and between 25.00 $\mathrm{kg}$ and $34.39 \mathrm{~kg}$ in men (Mendes, Alves \& Amaral, 2014).

\section{Nutrition impact symptoms (NIS)}

The NIS were measured with the Head and Neck Symptoms Checklist ${ }^{\circ}\left(\right.$ HNSC $\left.^{\circ}\right)$. This validated instrument aids in the early identification of symptoms that place HNC patients at risk of reductions in dietary intake, weight, and functional performance (Schmidt et al., 2013). This checklist had 12 of the symptoms included in the PG-SGA (pain, dry mouth, LOA, constipation, feeling full, diarrhoea, sore mouth, nausea, altered smell, vomiting, difficulty swallowing, and taste change) plus five additional symptoms (lack of energy, depression, difficulty chewing, thick saliva, and anxiety) which were not included in the PG-SGA but reported in the literature as being associated with reduced dietary intake (Schmidt et al., 2013). The HNSC ${ }^{\circ}$ also provided space for patients to record any additional NIS interfering with eating. Patients were asked to rate the severity of each symptom and the degree to which it interfered with eating (dietary intake) using a five-point Likert scale ranging from " $1=$ not at all" to " $5=$ a lot". A symptom was considered "present" if the severity score was at least 2 (Kubrak, Olson \& Baracos, 2013). All 17 symptom scores in the checklist were added together to make the total NIS score, which varied from 17 (no symptoms) to 85 (highest score of 5 for every symptom in the list) (Farhangfar et al., 2014).

\section{Statistical analysis}

All statistical analyses were performed using the IBM SPSS for Windows, version 23 (SPSS Inc, Chicago, USA). Data were checked for normality via ShapiroWilk analysis. All data were normally distributed as indicated by $p>0.05$, unless otherwise stated. If the data was not normally distributed, analysis was carried out on natural logarithm of the values to improve the symmetry and homoscedasticity of the distribution.

Descriptive statistics including percentages, means and standard deviation were used to describe demographic data, clinical characteristics, nutritional status, anthropometric data, biochemical data, NIS, energy and protein intakes. The mean values from both groups were compared by using an independent $t$-test. For ordinal data or data that were not normally distributed, Mann-Whitney U-test was carried out to test the differences between groups. Spearmen's rho was performed to evaluate the association between two numerical variables. Chi-square test was used to test the significant differences between groups for categorical data. A statistical probability of $p<0.05$ was considered as significant.

\section{RESULTS}

Fifty-four patients consented to participate in this study. A total of four patients were excluded as they did not meet the study's criteria. The recruitment for this study showed that there were more male than female patients with HNC (78\% versus $22 \%)$ and the median age of the population was 60 years with a range of 21-78 years old. More than half of the HNC patients in this study had nasopharynx ca ncer and 84\% were in an advanced stage of the tumour. In 
Table 1. Patient socio-demographic and clinical characteristics

\begin{tabular}{|c|c|c|c|c|}
\hline Characteristics & Overall $(n=50)$ & $\begin{array}{c}\text { Well } \\
\text { nourished } \\
(n=22)\end{array}$ & $\begin{array}{l}\text { Malnourished } \\
(n=28)\end{array}$ & p-value \\
\hline Age $\left(\right.$ years) ${ }^{\dagger}$, median (IQR) & 60 (49-67) & $54(44-67)$ & $61(52-66)$ & 0.163 \\
\hline $\begin{array}{l}\text { Gender }{ }^{\S}, \mathrm{n}(\%) \\
\text { Male } \\
\text { Female }\end{array}$ & $\begin{array}{l}39(78.0) \\
11(22.0)\end{array}$ & $\begin{array}{c}16(72.7) \\
6(27.3)\end{array}$ & $\begin{array}{c}23(82.1) \\
5(17.9)\end{array}$ & 0.425 \\
\hline $\begin{array}{l}\text { Ethnicitys, n (\%) } \\
\text { Malay } \\
\text { Chinese } \\
\text { Indian }\end{array}$ & $\begin{array}{l}21(42.0) \\
19(38.0) \\
10(20.0)\end{array}$ & $\begin{array}{l}9(40.9) \\
10(45.5) \\
3(13.6)\end{array}$ & $\begin{array}{l}12(42.9) \\
9(32.1) \\
7(25.0)\end{array}$ & 0.501 \\
\hline $\begin{array}{l}\text { Education level }{ }^{\S}, \mathrm{n}(\%) \\
\text { Primary or below } \\
\text { Secondary or above }\end{array}$ & $\begin{array}{l}20(40.0) \\
30(60.0)\end{array}$ & $\begin{array}{c}8(36.4) \\
14(63.6)\end{array}$ & $\begin{array}{l}12(42.9) \\
16(57.1)\end{array}$ & 0.642 \\
\hline $\begin{array}{l}\text { Marital status }{ }^{\S}, \mathrm{n}(\%) \\
\quad \text { Single } \\
\quad \text { Married }\end{array}$ & $\begin{array}{l}13(26.0) \\
37(74.0)\end{array}$ & $\begin{array}{c}4(18.2) \\
18(81.8)\end{array}$ & $\begin{array}{c}9(32.1) \\
19(67.9)\end{array}$ & 0.264 \\
\hline $\begin{array}{l}\text { Working status }{ }^{\S}, \mathrm{n}(\%) \\
\text { Yes } \\
\text { No }\end{array}$ & $\begin{array}{l}14(28.0) \\
36(72.0)\end{array}$ & $\begin{array}{c}6(27.3) \\
16(72.7)\end{array}$ & $\begin{array}{c}8(28.6) \\
20(71.4)\end{array}$ & 0.919 \\
\hline $\begin{array}{l}\text { Co-morbidities } \$ \text {, n }(\%) \\
\text { Yes } \\
\text { No }\end{array}$ & $\begin{array}{l}29(58.0) \\
21(42.0)\end{array}$ & $\begin{array}{l}12(54.5) \\
10(45.5)\end{array}$ & $\begin{array}{l}17(60.7) \\
11(39.3)\end{array}$ & 0.661 \\
\hline $\begin{array}{l}\text { Smoking history }{ }^{\S} \text {, n (\%) } \\
\text { Active smoker } \\
\text { Non-smoker } \\
\text { Ex-smoker }\end{array}$ & $\begin{array}{l}7(14.0) \\
25(50.0) \\
18(36.0)\end{array}$ & $\begin{array}{l}3(13.6) \\
14(63.6) \\
5(22.7)\end{array}$ & $\begin{array}{l}4(14.3) \\
11(39.3) \\
13(46.4)\end{array}$ & 0.164 \\
\hline $\begin{array}{l}\text { Alcohol history }{ }^{\S}, \mathrm{n}(\%) \\
\text { Yes } \\
\text { No }\end{array}$ & $\begin{array}{l}12(24.0) \\
38(76.0)\end{array}$ & $\begin{array}{c}6(27.3) \\
16(72.7)\end{array}$ & $\begin{array}{c}6(21.4) \\
22(78.6)\end{array}$ & 0.631 \\
\hline $\begin{array}{l}\text { Family history }{ }^{\S}, \mathrm{n}(\%) \\
\text { Yes } \\
\text { No }\end{array}$ & $\begin{array}{l}14(28.0) \\
36(72.0)\end{array}$ & $\begin{array}{c}7(31.8) \\
15(68.2)\end{array}$ & $\begin{array}{c}7(25.0) \\
21(75.0)\end{array}$ & 0.753 \\
\hline $\begin{array}{l}\text { Tumour location }{ }^{\Uparrow}, \mathrm{n}(\%) \\
\text { Tongue } \\
\text { Mouth } \\
\text { Salivary gland } \\
\text { Tonsil } \\
\text { Oropharynx } \\
\text { Nasopharynx } \\
\text { Sinuses } \\
\text { Larynx }\end{array}$ & $\begin{array}{c}7(14.0) \\
6(12.0) \\
3(6.0) \\
2(4.0) \\
2(2.0) \\
26(52.0) \\
1(2.0) \\
3(6.0)\end{array}$ & $\begin{aligned} 3 & (13.6) \\
2 & (9.1) \\
1 & (4.5) \\
0 & (0.0) \\
0 & (0.0) \\
15 & (68.2) \\
0 & (0.0) \\
1 & (4.5)\end{aligned}$ & $\begin{array}{rl}4 & (14.3) \\
4 & (14.3) \\
2 & (7.1) \\
2 & (7.1) \\
2 & (7.1) \\
1 & 1(39.3) \\
1 & (3.6) \\
2 & (7.1)\end{array}$ & 0.623 \\
\hline $\begin{array}{l}\text { Stage of tumour }{ }^{\S}, \mathrm{n}(\%) \\
\quad 1-2 \\
3-4\end{array}$ & $\begin{array}{c}8(16.0) \\
42(84.0)\end{array}$ & $\begin{array}{c}5(22.7) \\
17(77.3)\end{array}$ & $\begin{array}{c}3(10.7) \\
25(89.3)\end{array}$ & 0.277 \\
\hline $\begin{array}{l}\text { Type of treatment }{ }^{\S} \text {, n (\%) } \\
\text { Radiotherapy } \\
\text { Chemoradiotherapy }\end{array}$ & $\begin{array}{l}17(34.0) \\
33(66.0)\end{array}$ & $\begin{array}{c}7(31.8) \\
15(68.2)\end{array}$ & $\begin{array}{l}10(35.7) \\
18(64.3)\end{array}$ & 0.773 \\
\hline
\end{tabular}


Table 1. Patient socio-demographic and clinical characteristics (cont'd)

\begin{tabular}{|c|c|c|c|c|}
\hline Characteristics & Overall $(n=50)$ & $\begin{array}{c}\text { Well } \\
\text { nourished } \\
(n=22)\end{array}$ & $\begin{array}{l}\text { Malnourished } \\
(n=28)\end{array}$ & $p$-value \\
\hline $\begin{array}{l}\text { PG-SGA global rating } \\
\text { A (well-nourished) } \\
\text { B (moderately malnourished) } \\
\text { C (severely malnourished) }\end{array}$ & $\begin{array}{l}22(44.0) \\
18(36.0) \\
10(20.0)\end{array}$ & & & \\
\hline $\begin{array}{l}\text { Triage intervention } \\
\text { No intervention } \\
\text { (Score of } 0-1 \text { ) } \\
\text { Health education } \\
\text { (Score of } 2-3 \text { ) } \\
\text { Dietetic intervention } \\
\text { (Score of } 4-8 \text { ) } \\
\text { Critical interventions }(\geq 9)\end{array}$ & $\begin{array}{l}4(8.0) \\
13(26.0) \\
10(20.0) \\
23(46.0)\end{array}$ & & & \\
\hline $\begin{array}{l}\text { BMI category }{ }^{\uparrow} \\
\text { Underweight }(<18.5 \mathrm{~kg} / \mathrm{m} 2) \\
\text { Normal weight }(18.5-24.9 \mathrm{~kg} / \mathrm{m} 2) \\
\text { Overweight }(25-29.9 \mathrm{~kg} / \mathrm{m} 2) \\
\text { Obese }(>30 \mathrm{~kg} / \mathrm{m} 2)\end{array}$ & $\begin{array}{l}12(24.0) \\
25(50.0) \\
5(10.0) \\
8(16.0)\end{array}$ & $\begin{array}{c}3(13.6) \\
13(59.1) \\
1(4.5) \\
5(22.7)\end{array}$ & $\begin{array}{l}9(32.1) \\
12(42.9) \\
4(14.3) \\
3(10.7)\end{array}$ & 0.224 \\
\hline $\begin{array}{l}\text { Pre-treatment weight loss } \pi \\
\text { None } \\
<5 \% \text { in } 1 \text { month or }<10 \% \text { in } 6 \\
\text { months } \\
\geq 5 \% \text { in } 1 \text { month or } \geq 10 \% \text { in } 6 \\
\text { months }\end{array}$ & $\begin{array}{l}14(28.0) \\
30(60.0) \\
6(12.0)\end{array}$ & $\begin{array}{l}12(54.4) \\
10(45.5)\end{array}$ & $\begin{array}{c}2(7.1) \\
20(71.4) \\
6(21.4)\end{array}$ & $<0.001$ \\
\hline $\begin{array}{l}\text { Nutrition Impact Symptoms (NIS) } \\
\text { Yes } \\
\text { No }\end{array}$ & $\begin{array}{l}40(80.0) \\
10(20.0)\end{array}$ & $\begin{array}{l}14(63.6) \\
8(36.4)\end{array}$ & $\begin{array}{r}26(92.9) \\
2(7.1)\end{array}$ & 0.014 \\
\hline $\begin{array}{l}\text { Dietitian referral } \\
\text { Yes } \\
\text { No }\end{array}$ & $\begin{array}{l}23(46.0) \\
27(54.0)\end{array}$ & $\begin{array}{c}14(63.6) \\
8(36.4)\end{array}$ & $\begin{array}{c}9(32.1) \\
19(67.9)\end{array}$ & 0.045 \\
\hline
\end{tabular}

Note: NA: not applicable

${ }^{\dagger}$ Mann-Whitney U test

sChi-square test for proportions

"Fisher's exact test.

$p<0.05$ shows the significant difference between well-nourished (PG-SGA category A) and malnourished patients (PG-SGA category B/ PG-SGA category C)

addition, 33 (66\%) received CCRT while $17(34 \%)$ received RT only. All patients received a total of 60Gy and above 30 fractions radiation dosage (Table 1 ).

The prevalence of pre-treatment malnutrition was 56\% (PG-SGA category B and PG-SGA category C), with 20\% severely malnourished (PG-SGA category C) (Table 1). The median score for PGSGA was 7 , indicating a requirement for dietetic intervention. More than $50 \%$ of the malnourished HNC patients were in advanced stage. There were no significant differences between malnutrition status with gender and ethnic groups.

Mean body weight was $60.24 \pm 14.73$ $\mathrm{kg}$ with $43.03 \pm 8.12 \mathrm{~kg}$ muscle mass. Half of the HNC patients had a normal BMI before treatment, followed by $24 \%$ underweight, $16 \%$ obese and $10 \%$ overweight (Table 1). About $72 \%$ HNC patients had weight loss before treatment, 
Neoh MK, Zalina AZ, Zuwariah AR et al.

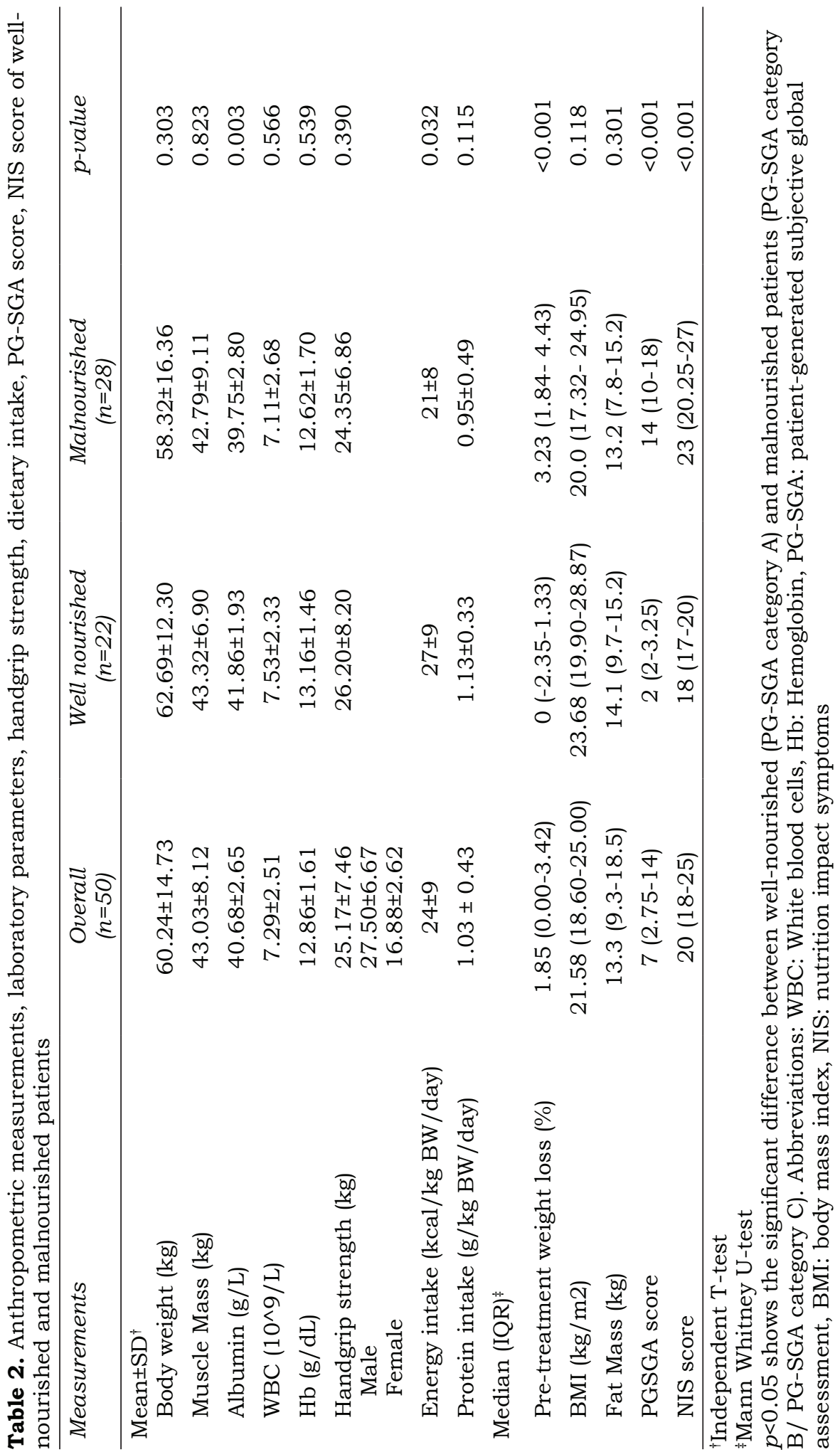


Table 3. Nutrition Impact Symptoms (NIS) interference scores from the Head and Neck Symptoms Checklist (HNSCO) of the patients $(n=50)$

\begin{tabular}{lccccc}
\hline $\begin{array}{l}\text { NIS interference score } \\
(1-5)\end{array}$ & $\begin{array}{c}\text { Prevalence } \\
n(\%)\end{array}$ & $\begin{array}{c}\text { Median } \\
(\text { IQR })\end{array}$ & $\begin{array}{c}\text { Well } \\
\text { nourished } \\
(n=22)\end{array}$ & $\begin{array}{c}\text { Malnourished } \\
(n=28)\end{array}$ & $p$-value \\
\hline Taste change & $5(10)$ & $1(1-1)$ & $1(1-1)$ & $1(1-1)$ & 0.039 \\
Difficulty swallowing & $9(18)$ & $1(1-1)$ & $1(1-1)$ & $1(1-2)$ & 0.004 \\
Difficulty chewing & $26(52)$ & $2(1-3.25)$ & $1(1-2)$ & $2.50(1-4)$ & 0.017 \\
Constipation & $8(16)$ & $1(1-1)$ & $1(1-1)$ & $1(1-1.75)$ & 0.048 \\
Loss of appetite & $19(38)$ & $1(1-2)$ & $1(1-1)$ & $2(1-3)$ & 0.001 \\
Dry mouth & $19(38)$ & $1(1-2)$ & $1(1-1)$ & $2(1-2)$ & 0.011 \\
Pain & $11(22)$ & $1(1-1)$ & $1(1-1)$ & $1(1-2.75)$ & 0.007 \\
Anxious & $9(18)$ & $1(1-1)$ & $1(1-1)$ & $1(1-1)$ & 0.455 \\
Nausea & $4(8)$ & $1(1-1)$ & $1(1-1)$ & $1(1-1)$ & 0.197 \\
Lack of Energy & $14(28)$ & $1(1-2)$ & $1(1-1)$ & $1(1-2)$ & 0.057 \\
Sore mouth & $6(12)$ & $1(1-1)$ & $1(1-1)$ & $1(1-1)$ & 0.155 \\
Diarrhoea & $0(0)$ & $1(1-1)$ & $1(1-1)$ & $1(1-1)$ & 1.000 \\
Thick saliva & $12(24)$ & $1(1-1.25)$ & $1(1-1)$ & $1(1-2)$ & 0.107 \\
Depressed & $2(4)$ & $1(1-1)$ & $1(1-1)$ & $1(1-1)$ & 0.863 \\
Fullness & $4(8)$ & $1(1-1)$ & $1(1-1)$ & $1(1-1)$ & 0.455 \\
Vomiting & $3(6)$ & $1(1-1)$ & $1(1-1)$ & $1(1-1)$ & 0.704 \\
Smell bothersome & $6(12)$ & $1(1-1)$ & $1(1-1)$ & $1(1-1)$ & 0.716 \\
\hline
\end{tabular}

Note: Prevalence of NIS when severity scores $\geq 2$; Mann-Whitney U test for skewed data $p<0.05$ shows the significant difference between well-nourished (PG-SGA category A) and malnourished patients (PG-SGA category B/PG-SGA category C)

with $12 \%$ having critical weight loss of $\geq 5 \%$. The median percentage of weight loss at the beginning of treatment from all 50 patients was $1.85 \%$, with a range of $0 \%$ to $3.42 \%$ (Table 2). There was a significant difference in pre-treatment weight loss between well-nourished and malnourished patients. There was a weak positive relationship between pretreatment weight loss and NIS ( $r=0.332$, $p=0.019$ ), which indicated that those with higher NIS scores experienced higher pre-treatment weight loss (Table 5). However, there were no significant associations between pre-treatment weight loss with albumin, energy intake, and protein intake (Table 5).

About $80 \%$ HNC patients had NIS before the start of treatment, with only $20 \%$ of patients experiencing none of the
17 symptoms listed (Table 2). Almost all malnourished HNC patients had NIS symptoms compared to $63.6 \%$ among those well-nourished. Well-nourished patients had a statistically better total NIS score compared to malnourished patients. There were seven significant differences in NIS between wellnourished and malnourished patients including taste change, constipation, difficulty chewing, difficulty swallowing, dry mouth, LOA and pain around tumour (Table 3). More than half of the HNC patients had the symptom of difficulty in chewing before treatment (Table 3).

The energy intake and protein intakes of HNC patients in this study were $24 \pm 9 \mathrm{kcal} /$ day and $1.03 \pm 0.43 \mathrm{~g} /$ day, respectively. About $72 \%$ HNC patients were on normal diet, $10 \%$ on soft diet, 
Table 4. Correlation between independent variables and PG-SGA total score $(n=50)$

\begin{tabular}{lcc}
\hline Independent variables & Relationship $(r)$ & Significance $(p)$ \\
\hline NIS score & 0.731 & $<0.001$ \\
Albumin $(\mathrm{g} / \mathrm{L})$ & -0.278 & 0.05 \\
Energy intake $(\mathrm{kcal} / \mathrm{kg} \mathrm{BW} / \mathrm{d})$ & -0.342 & 0.015 \\
Protein intake $(\mathrm{g} / \mathrm{kg} \mathrm{BW} / \mathrm{d})$ & -0.386 & 0.006
\end{tabular}

Spearmen's rho $p<0.05$ shows significant association

Abbreviations: PG-SGA: patient-generated subjective global assessment, NIS: nutrition impact symptoms

Table 5. Correlation between independent variables and pre-treatment weight loss $(n=50)$

\begin{tabular}{lcc}
\hline Independent variables & Relationship $(r)$ & Significance $(p)$ \\
\hline NIS score & 0.332 & 0.019 \\
Albumin $(\mathrm{g} / \mathrm{L})$ & -0.245 & 0.087 \\
Energy intake $(\mathrm{kcal} / \mathrm{kg} \mathrm{BW} / \mathrm{d})$ & 0.20 & 0.892 \\
Protein intake $(\mathrm{g} / \mathrm{kg} \mathrm{BW} / \mathrm{d})$ & 0.068 & 0.638 \\
\hline
\end{tabular}

Spearmen's rho $p<0.05$ shows significant association

Abbreviations: PG-SGA: patient-generated subjective global assessment, NIS: nutrition impact symptoms

$6 \%$ on minced diet, $10 \%$ on blended diet and $2 \%$ on full liquid diet. The energy and protein intakes for well-nourished and malnourished patients were $27 \pm 9$ $\mathrm{kcal} / \mathrm{kg}$ BW/day and $1.13 \pm 0.33 \mathrm{~g} / \mathrm{kg}$ $\mathrm{BW} /$ day, and $21 \pm 8 \mathrm{kcal} / \mathrm{kg} \mathrm{BW} /$ day and $0.95 \pm 0.49 \mathrm{~g} / \mathrm{kg} \quad \mathrm{BW} /$ day (Table $2)$. Significant difference was found in energy intake between well-nourished and malnourished patients $(p<0.05)$. A majority of HNC patients $(90 \%)$ were not on any oral nutritional supplement (ONS) support at the beginning of treatment. There were only $14.2 \%$ malnourished HNC patients on ONS before treatment.

All HNC patients had normal albumin with a mean \pm standard deviation $(S D)$ of $40.7 \pm 0.4 \mathrm{~g} / \mathrm{L}$. Furthermore, mean $\mathrm{Hb}$ value for both male $(13.1 \pm 0.3 \mathrm{~g} / \mathrm{L})$ and female $(12.0 \pm 0.4 \mathrm{~g} / \mathrm{L})$ patients were at normal values as well. WBC was within the normal range with means of $7.3 \pm 0.4$ $10^{\wedge} 9 / \mathrm{L}$. There were no significant differences between $\mathrm{WBC}$ and $\mathrm{Hb}$ of patients who were well-nourished $(p=0.566)$ and malnourished $(p=0.539)$, according to PG-SGA. Based on gender, the overall reading for males was better than females, which were $27.50 \pm 6.67 \mathrm{~kg}$ and $16.88 \pm 2.62 \mathrm{~kg}$, respectively.

Out of 50 HNC patients, only 23 patients $(46 \%)$ had been referred to a dietitian before the start of treatment (Table 1). However, around 70\% malnourished patients had no dietitian referral. There was a significant difference in dietitian referral between well-nourished and malnourished patients, $p=0.045$.

Table 4 shows there were significant negative relationships between energy intake $(r=0.492, p<0.001)$ and protein intake $(r=0.478 ; p<0.001)$ with PG-SGA; which indicated lower energy and protein intakes related with poor nutritional status (lower mean score of PG-SGA). A significant strong association with PG-SGA was observed for NIS score $(r=0.731, p<0.001)$, indicating the better the nutritional status, the lower the NIS of the HNC patients. 


\section{DISCUSSION}

The prevalence of malnutrition in this study was high (56\%). Similar findings were obtained from other studies using PG-SGA on patients with cancer, which also reported $42 \%$ to $76 \%$ patients either being malnourished or at risk of being malnourished (Bauer et al., 2002; Luis et al., 2007). It is a concern that $>50 \%$ HNC patients had malnutrition problems before starting RT or CCRT, which can further worsen their nutritional status with treatment-related symptoms. Untreated malnutrition has been associated with reduced response towards treatment, poor survival and a diminished quality of life (Santarpia, Contaldo \& Pasanisi, 2011). Therefore, it is crucial to maintain an optimal nutritional status for patients before treatment for better outcomes and reduce complications such as treatment interruption (Lin et al., 2005).

Weight loss remains a clinically relevant, simple, and reliable marker of malnutrition. Our study reported that $12 \%$ HNC patients had a critical weight loss $\geq 5 \%$ in one month. Langius et al. (2016) revealed a similar result in a study of HNC patients where $16 \%$ of the patients had critical weight loss $(>5 \%)$ before treatment. Another study reported that at the time of diagnosis, 34\% of patients with oral/oropharyngeal cancer had already lost $\geq 10 \%$ of body weight in six months or $\geq 5 \%$ in one month (JagerWittenaar et al., 2007). Weight loss of $\geq 10 \%$ in six months or $\geq 5 \%$ in one month has been shown to increase complication rates, such as impaired wound healing, reduced immune function and decreased tolerance towards surgery, RT and chemotherapy. The outcomes may lead to higher mortality and reduced quality of life (van Bokhorst-de van der Schueren et al., 1997).

Although there was no significant difference for handgrip strength among well-nourished and malnourished groups, the handgrip strength of HNC patients in this study was categorised as intermediate strength when compared to a previous study on cancer patients (Mendes et al., 2014). This indicated that cancer patients may experience some muscle wasting due to diminished synthesis of muscle protein and increased degradation of proteins (Kilgour et al., 2013; Chen et al., 2011).

There was a significant difference in NIS (taste change, difficulty swallowing, difficulty chewing, constipation, LOA, dry mouth and pain) between wellnourished and malnourished patients. Neoadjuvant chemotherapy prior to $\mathrm{RT}$ is one of the reasons HNC patients experience LOA, dry mouth, lack of energy, thick saliva, and pain. Farhangfar et al. (2014)'s study reported that LOA, difficulty chewing, dry mouth and pain were symptoms associated with reduced dietary intake. Most of the malnourished patients experienced reduced dietary intake due to these symptoms. This study found that the malnourished group had a lower dietary intake compared to the well-nourished group. The average daily energy and protein intakes in this study were below the European Society for Clinical Nutrition and Metabolism (ESPEN) recommended guidelines of 30 - $35 \mathrm{kcal} / \mathrm{kg}$ of body weight and 1.2 $1.6 \mathrm{~g} / \mathrm{kg}$ body weight. Advanced staging showed a significant association with decreased energy and protein intakes, and nutritional depletion, according to Ravasco et al. (2003)'s study on HNC patients. In our study, majority of HNC patients were in advanced stage and were found to have a higher tendency of nutritional depletion with inadequate energy and protein intakes, which marked the same nutrition intake deficits with the earlier mentioned study.

In our study, there was a significant relationship between pre-treatment weight loss with NIS score. Multiple NIS are more likely to reduce dietary intake and induce weight loss. Half of the HNC patients had the symptom of difficulty in 
chewing. Most patients with oral cancer are edentulous or partially dentate, which adversely affects their masticatory function (Farhangfar et al., 2014). Postdental extraction before treatment might expose patients to difficulty in chewing hard solid foods and thus lead to pretreatment weight loss. Patients having chewing problems have been seen changing their diet into a soft, mashed or liquid diet. As nutritional density of a mashed or liquid diet is lower than that of a solid diet, these patients are at a high risk of malnutrition too. For those patients who have received early nutrition management before treatment where they are advised to use energy and protein enriched liquid dietary supplements, the use of these supplements increases energy and protein intakes and in turn decreases the risk for malnutrition (Nejatinamini et al., 2018). For a patient who is having NIS prior to RT, especially one who is malnourished, ONS initiation should be implemented as soon as at the beginning of RT.

The timing of nutritional intervention is fairly important. This study revealed that malnutrition could happen before RT commencement and perhaps at the time of diagnosis. Jager-Wittenaar et al. (2017)'s exploratory study suggested a high prevalence of cachexia (42\%) in patients with newly diagnosed HNC. There was about 54\% HNC patients in this study who have had no dietitian referral prior to $\mathrm{RT}$ and this remains a concern in clinical oncology. Majority of malnourished patients in this study were unable to start their treatment in optimal nutritional status due to the lack of dietitian referral, with only $32.1 \%$ receiving nutrition management. This result is similar to other studies that reported only $30 \%$ to $60 \%$ of cancer patients at risk of malnutrition having received nutritional treatment, and even patients diagnosed with severe malnutrition failed to receive an appropriate nutritional intervention
(Attar et al., 2012; Segura et al., 2005). A significant number of cancer patients at risk of malnutrition remain undetected due to the lack of nutrition screening during diagnosis and absence of nutritional evaluation as part of routine practice in the clinical setting (Koom, Ahn \& Song, 2012). According to the Clinical Oncology Society of Australia, malnutrition screening should be undertaken by all patients at diagnosis to identify those at nutritional risk, and then repeated at intervals through each stage of treatment.

The factors associated with malnutrition in this study included high pre-treatment weight loss, high NIS score, reduced energy and protein intakes. Our study is consistent with another HNC patients study which found that malnutrition was significantly associated with multiple NIS, reduced dietary intake, and involuntary weight loss (Schmidt et al., 2013). Patients with HNC should be nutritionally screened using a validated screening tool (PG-SGA or SGA) and NIS checklist at diagnosis.

The strength of the current study was the rich data of nasopharynx patients among all other categories of HNC such as laryngeal, tonsil and tongue. The results serve as a reference and benchmark for further research on particular types of nasopharynx cancer. At the same time, NIS of HNC patients were observed clearly with a validated HNSC $\subset$ that allowed us to design a more effective nutrition intervention in future. To the best of our knowledge, our study was the first in Malaysia to examine the association between nutritional status with energy intake, protein intake and NIS in HNC patients at the beginning of RT.

Limitations of this study were the inherently limited single-institution design with only HNC in-patients as opposed to having data on outpatients across multiple institutions, thus making it difficult to draw stronger conclusions. This study has only observed the 
nutritional status of $\mathrm{HNC}$ patients at the beginning of RT, therefore, it is suggested that a further observational study at diagnosis could be done in order to generate a more comprehensive data on the nutritional status among HNC patients. Long-term follow-up is proposed to enable an investigation of any associations between pre-treatment nutritional status with treatment outcomes.

\section{CONCLUSION}

In summary, $56 \%$ of patients from this study were malnourished and $20 \%$ were severely malnourished at the beginning of RT. However, the lack of dietary counselling has led to higher risks of malnutrition among HNC patients before RT. In addition, this study showed that malnourished HNC patients experienced higher NIS scores, and reduced energy and protein intakes at the beginning of RT. More than half of the HNC patients had the symptom of chewing difficulty. Our study provided important preliminary data suggesting that early identification of malnutrition and dietitian referral before treatment commencement are warranted. Our results have presented the need for active nutritional status screening including NIS assessment at cancer diagnosis apart from at the beginning of treatment. Early identification of the nutritional status of patients at presentation ensures optimal nutritional status to improve overall treatment outcomes.

\section{Acknowledgements}

The author would like to express a sincere appreciation to the General Director of the Ministry of Health, Malaysia for approval of this study, as well as the department of administration, National Cancer Institute, Putrajaya for assistance in this study. Besides, we thank all the patients who have participated and contributed in this study.

\section{Authors' contributions}

NMK, principal investigator, conceptualised and designed the study, prepared the draft of the manuscript and reviewed the manuscript; ZAR, NJ, advised on the data analysis and interpretation, and reviewed the manuscript; SNAS, AA, HCY, BSHL, NWH, AMM, led the data collection and reviewed the manuscript; $Z A Z$, advised on data analysis and interpretation, assisted in drafting of the manuscript, reviewed the manuscript; NBMY, ZI, ZAMD reviewed the manuscript.

\section{Conflict of interest}

All authors declare that they have no conflict of interest with any party in relation to this manuscript.

\section{References}

Attar A, Malka D, Sabate JM, Bonnetain F, Lecomte T, Aparicio T, Locher C, Laharie D, Ezenfis J \& Taieb J (2012). Malnutrition is high and underestimated during chemotherapy in gastrointestinal cancer: an AGEO prospective cross-sectional multicenter study. Nutr Cancer 64(4):535-42.

Azizah AM, Nor Saleha IT, Noor Hashimah A, Asmah ZA \& Mastulu W (2015). Malaysian National Cancer Registry Report 2007-2011. Ministry of Health Malaysia, Putrajaya.

Bauer J, Capra S \& Ferguson M (2002). Use of the scored Patient-Generated Subjective Global Assessment (PG-SGA) as a nutrition assessment tool in patients with cancer. Eur J Clin Nutr 56(8): 779-785. https://doi. org/10.1038/sj.ejcn.1601412.

Bower MR \& Martin RC (2009). Nutritional management during neoadjuvant therapy for esophageal cancer. J Surg Oncol 100(1): 82-87.

Chaturvedi AK, Anderson WF, Lortet-Tieulent J, Paula CM, Ferlay J, Franceschi S, Rosenberg PS, Bray F \& Gillison ML (2013). Worldwide trends in incidence rates for oral cavity and oropharyngeal cancers. J Clin Oncol 31(36): 4550-4559. JCO.2013.50.3870.

Chen C, Ho-Chang, Huang Y \& Hung T (2011). Hand-grip strength is a simple and effective outcome predictor in esophageal cancer following esophagectomy with reconstruction : a prospective study. J Cardiothorac Surg. 6(98): 1-5. https://doi.org/ 10.1186/1749-8090-698.

Evans WJ, Morley JE, Argiles J, Bales C, Baracos V, Guttridge D, Jatoi A, Kalantar-Zadeh K, Lochs H, Mantovani G, Marks D, Mitch WE, Muscaritoli M, Najand A, Ponikowski P, Rossi Fanelli F, Schambelan M, Schols A, Schuster M, Thomas D, Wolfe R \& Anker SD (2008) Cachexia: a new definition. Clin Nutr 27 (6):793-799. 
Farhangfar A, Makarewicz M, Ghosh S, Jha N, Scrimger R, Gramlich L \& Baracos V (2014). Nutrition impact symptoms in a population cohort of head and neck cancer patients: Multivariate regression analysis of symptoms on oral intake, weight loss and survival. Oral Oncology 50(9): 877-883. https://doi. org/10.1016/j.oraloncology.2014.06.009.

Jager-Wittenaar H, Dijkstra PU, Vissink A, Van Der Laan BFAM, Van Oort RP \& Roodenburg JLN (2007). Critical weight loss in head and neck cancer-prevalence and risk factors at diagnosis: an explorative study. Support Care Cancer 15(9): 1045-1050. https://doi. org/10.1007/s00520-006-0212-9.

Jager-Wittenaar H, Dijkstra PU, Dijkstra G, Bijzet J, Langendijk JA, van der Laan BF \& Roodenburg JL (2017). High prevalence of cachexia in newly diagnosed head and neck cancer patients: An exploratory study. Nutrition 35: 114-118.

Kilgour RD, Vigano A, Trutschnigg B, Lucar E, Borod M \& Morais JA (2013). Handgrip strength predicts survival and is associated with markers of clinical and functional outcomes in advanced cancer patients. Support Care Cancer 21(12): 3261-3270.

Koom WS, Ahn SD, Song SY, Lee CG, Moon SH, Chie EK, Jang HS, Oh YT, Lee HS \& Keum KC (2012). Nutritional status of patients treated with radiotherapy as determined by subjective global assessment. Radiat Oncol J 30(3):132.

Kubrak C, Olson K \& Baracos VE (2013). The head and neck symptom checklist?: An instrument to evaluate nutrition impact symptoms effect on energy intake and weight loss. Support Care Cancer 21(11):3127-36. https://doi. org/10.1007/s00520-013-1870-z.

Kubrak C, Olson KR, Jha N, Jensen L, Mccargar L, Seikaly H, Harris J, Scrimger R, Parliament M \& Baracos VE (2010). Nutrition impact symptoms: key determinants of reduced dietary intake, weight loss, and reduced functional capacity of patients with head and neck cancer before treatment. Head Neck 32: 290-300. https://doi.org/10.1002/ hed. 21174 .

Langius JAE, Twisk J, Kampman M, Doornaert P, Kramer $\mathrm{MHH}$, Weijs PJM \& Leemans CR (2016). Prediction model to predict critical weight loss in patients with head and neck cancer during (chemo)radiotherapy. Oral Oncology 52(January 2016): 91-96. https:// doi.org/10.1016/j.oraloncology.2015.10.021.

Lees $J$ (1999). Incidence of weight loss in head and neck cancer patients on commencing radiotherapy treatment at a regional oncology centre. Eur J Cancer Care (Engl) 8(3):133-6.
Lin A, Jabbari S, Worden FP, Bradford CR, Chepeha DB, Teknos TN, Liao JJ, Nyquist GG, Tsien C, Schipper MJ, Urba S, Wolf GT \& Eisbruch A (2005). Metabolic abnormalities associated with weight loss during chemoirradiation of head-and-neck cancer. Int $J$ Radiat Oncol Biol Phys 63(5): 1413-1418.

Luis DADE, Izaola O \& Aller R (2007). Nutritional status in head and neck cancer patients. Eur Rev Med Pharmacol Sci. 11(4): 239-243.

Mendes J, Alves P, Amaral TF. Comparison of nutritional status assessment parameters in predicting length of hospital stay in cancer patients. Clin Nutr 2014;33(3):466-470.

Nejatinamini S, Kubrak C, Álvarez-Camacho M, Baracos VE, Ghosh S, Wismer WV \& Mazurak VC (2018). Head and Neck Cancer Patients Do Not Meet Recommended Intakes of Micronutrients without Consuming Fortified Products. Nutr Cancer 70(3): 474-482. https:// doi.org/10.1080/01635581.2018.1445767.

Ottery FD, McCallum PD \& Polisena CG (2000). The clinical guide to oncology nutrition. Patient generated subjective global assessment. The American Dietetic Association, Chicago, IL.

Prevost V, Joubert C, Heutte N \& Babin E (2014). Assessment of nutritional status and quality of life in patients treated for head and neck cancer. Eur Ann Otorhinolaryngol Head Neck Dis 131(2):113-120.

Ravasco P, Monteiro-Grillo I, Vidal PM \& Camilo ME (2003). Nutritional deterioration in cancer: the role of disease and diet. Clin Oncol 15(8): 443-450.

Righini C, Timi N, Junet P, Bertolo A, Reyt E \& Atallah I (2013). Assessment of nutritional status at the time of diagnosis in patients treated for head and neck cancer. Eur Ann Otorhinolaryngol Head Neck Dis 130(1): 8-14. https://doi.org/10.1016/j.anorl.2012.10.001.

Santarpia L, Contaldo F \& Pasanisi F (2011). Nutritional screening and early treatment of malnutrition in cancer patients. $J$ Cachexia Sarcopenia Muscle 2(1):27-35.

Schmidt KN, Olson K, Kubrak C, Parliament M $\&$ Ghosh S (2013). Validation of the head and neck patient symptom checklist as a nutrition impact symptom assessment tool for head and neck cancer patients. Support Care Cancer 21(1):27-34. https://doi.org/10.1007/ s00520-012-1483-y. 
Segura A, Pardo J, Jara C, Zugazabeitia L, Carulla $\mathrm{J}$, de las Peñas R, García-Cabrera E, Azuara ML, Casadó J \& Gómez-Candela C (2005). An epidemiological evaluation of the prevalence of malnutrition in Spanish patients with locally advanced or metastatic cancer. Clin Nutr 24(5):801-14.

Spiro A, Baldwin C, Patterson A, Thomas J \& Andreyev HJN (2006). The views and practice of oncologists towards nutritional support in patients receiving chemotherapy. $\mathrm{Br} J$ Cancer 95(4): 431.

Stewart BW \& Wild CP (2014). World cancer report 2014. Lyon: International Agency for Research on Cancer, 16-69.
Van Bokhorst-de van der Schueren MA, van Leeuwen PA, Sauerwein HP, Kuik DJ, Snow GB \& Quak JJ (1997) Assessment of malnutrition parameters in head and neck cancer and their relation to postoperative complications. Head Neck 19(5):419-425.

Van den Berg MG, Rasmussen-Conrad EL, Gwasara GM, Krabbe PF, Naber AH \& Merkx MA (2006). A prospective study on weight loss and energy intake in patients with head and neck cancer, during diagnosis, treatment and revalidation. Clin Nutr 25(5): 765-772. https:/ / doi.org/10.1016/j.clnu.2005.12.007. 